University of Nebraska - Lincoln

DigitalCommons@University of Nebraska - Lincoln

October 1969

\title{
A Technique for the Rapid Measurement of Thermoelectric Power
}

\author{
G.R. Caskey \\ Center for Materials Science and Engineering, Cambridge, Massachusetts \\ David J. Sellmyer \\ University of Nebraska-Lincoln, dsellmyer@unl.edu \\ L.G. Rubin \\ Francis Bitter National Magnet Laboratory, Massachusetts Institute of Technology, Cambridge, \\ Massachusetts
}

Follow this and additional works at: https://digitalcommons.unl.edu/physicssellmyer

Part of the Physics Commons

Caskey, G.R.; Sellmyer, David J.; and Rubin, L.G., "A Technique for the Rapid Measurement of Thermoelectric Power" (1969). David Sellmyer Publications. 188.

https://digitalcommons.unl.edu/physicssellmyer/188

This Article is brought to you for free and open access by the Research Papers in Physics and Astronomy at DigitalCommons@University of Nebraska - Lincoln. It has been accepted for inclusion in David Sellmyer Publications by an authorized administrator of DigitalCommons@University of Nebraska - Lincoln. 
mocouple wire, has impregnated the ceramic insulation with epoxy at 7 kilobars and has used the resulting feedthroughs at up to 7 kilobars with helium. ${ }^{21}$ We have used a pressure of 0.5 kilobar for the impregnation, and the resulting feedthroughs have been found to withstand at least 2.7 kilobars of helium. A very fluid unfilled epoxy ${ }^{22}$ is used and the MgO then becomes, in effect, the filler for the epoxy. The thermocouple wire is silver soldered into a fitting such that the liquid epoxy can be allowed to stand over the exposed end of the ceramic insulation, and a mold release compound is applied to the fitting around the wire so that the excess epoxy may be removed after the impregnation is complete. A pressure of 0.5 kilobar is

${ }^{21}$ P. L. M. Heydemann, Rev. Sci. Instrum. 38, 558 (1967).

22 Eccoseal W-19 with catalyst 11, made by Emerson and Cuming, Canton, Mass. applied to the epoxy, and a vacuum is applied to the other end of a $30 \mathrm{~cm}$ length of the wire. It ordinarily requires two days for the epoxy to harden, but when pressurized with helium, it is still jelly-like after three days. It is not known whether the longer curing time results from the lack of oxygen or from the increase in pressure. At an applied pressure of 0.5 kilobar the epoxy was found to penetrate in three days to a depth of $3.2 \mathrm{~cm}$ into the $\mathrm{MgO}$ in a $0.16 \mathrm{~cm}$ diam sheath.

We gratefully acknowledge the support of the Department of Physics of the University of Southern California, the National Science Foundation, and the National Aeronautics and Space Administration. We also acknowledge the helpful suggestions of F. F. Bayer of Emerson and Cuming, Gardena, California and the constructive comments on this article made by J. E. Schirber of the Sandia Corporation, Albuquerque, New Mexico.

\title{
A Technique for the Rapid Measurement of Thermoelectric Power*
}

\author{
G. R. CASKey $\dagger$ AND D. J. Selchyyer \\ Center for Materials Science and Engineering, \\ AND \\ L. G. RuBIN \\ Francis Bitter National Magnet Laboratory, $\ddagger$ Massachusetts Institute of Technology, \\ Cambridge, Massachusetts 02139 \\ (Received 22 May 1969)
}

\begin{abstract}
A new technique is described for rapid measurement of the thermoelectric power of rod-shaped specimens over a wide temperature range. The apparatus utilizes sensitive commercial dc amplifier for the sample and temperature gradient voltages and a multiple-point recorder for sampling these voltages as well as the sample temperature signal. The technique eliminates spurious thermal emf's in the leads and is based upon on-the-run recording of the sample and temperature gradient voltages as the temperature gradient slowly increases. As a test of this technique, the thermopower of pure nickel was measured between 4.2 and $300 \mathrm{~K}$ and the results are compared with other measurements using conventional techniques.
\end{abstract}

\section{INTRODUCTION}

$T^{\prime}$ HERE are two basic techniques for the measurement of thermoelectric power : the integral and differential. ${ }^{1}$ In the integral method, one end of a rather long wire specimen is held at a fixed temperature such as $4.2 \mathrm{~K}$ and the other end is heated to a temperature $T$, where $T$ is made to vary through the temperature range of interest; the thermal emf of the specimen lead-wire couple $V(T)$ is measured and the thermoelectric power of the couple is

\footnotetext{
* Research supported by the Advanced Research Projects Agency. $\dagger$ Present address: E. I. duPont de Nemours and Co., Savannah River Laboratory, Aiken, South Carolina.

$\ddagger$ Supported by the United States Air Force Office of Scientific Research.

${ }^{1}$ See, for example, G. K. White, Experimental Techniques in LowTemperature Physics (Oxford University Press, London, 1959).
}

given by

$$
S(T)=d V(T) / d T \text {. }
$$

However, with single crystal samples or brittle materials it is necessary to measure $S(T)$ with the differential method in which rather short rod-type specimens are used. In this method, a small temperature gradient $\Delta T$ is maintained across the specimen which gives rise to a thermal emf $\Delta V$; the thermoelectric power of the couple is then given by

$$
S(T)=\Delta V(T) / \Delta T .
$$

For this relation to be valid, the temperature difference along the specimen must be small enough that structure in $S(T)$ is not smeared out, the specimen must be homogeneous, and the temperatures must be uniform in the 
vicinity of connections between dissimilar metals in the measuring circuit.

The usual problems encountered in measurement of thermoelectric power are maintenance of a constant temperature over a long period of time, maintenance of a constant temperature gradient, and elimination of spurious thermal voltages arising within the circuit. The first two problems may be eliminated by suitable control circuits. Recently, Rowe ${ }^{2}$ has shown how to obviate the last problem by a sequence of measurements of thermoelectric voltage $\left(\Delta V_{i}\right)$ for small incremental stepwise increases in the temperature gradient $\left(\Delta T_{i}\right)$. A plot of corresponding values of thermoelectric voltage against temperature gradient is linear and the slope of the line yields the thermoelectric power of the thermocouple. However, this procedure is time consuming since a steady state must be established for each increment in $\Delta T$, and several increments are required to properly evaluate the thermoelectric power at any one temperature. A more rapid procedure, as described below, was developed based on the simultaneous measurement of $\Delta T$ and $\Delta V$ as the temperature gradient was slowly increased. This procedure was tested by measurement of the thermoelectric power of pure nickel and was successfully applied to the measurement of the thermoelectric power of over 20 specimens over the temperature range from 4.2 to $300 \mathrm{~K}^{3}$

\section{DISCUSSION}

Measurements of thermoelectric power on rod-shaped specimens ( $4 \mathrm{~mm}$ diam by $3 \mathrm{~cm}$ long) were made with the circuit illustrated in Fig. 1. The specimen and heaters were sealed in an evacuated stainless steel can that was immersed in liquid helium or liquid nitrogen. Specimen temperature was controlled by the current to the main heater and a thermal gradient was generated by current in the small heater on the free end of the specimen.

The thermoelectric voltage generated by the specimen and the voltage output of the differential thermocouple were amplified by Keithley model 147 nanovolt null detectors. Their output was filtered with a simple $\mathrm{RC}$ filter to reduce ac pickup and attenuated to $10 \mathrm{mV}$ maximum, the limiting input voltage for the recorder. The platinum resistance thermometer and the carbon resistor were parts of a circuit that provided a regulated current such that the voltage drop across the resistor was always between 0 and $10 \mathrm{mV}$ regardless of which of several resistance ranges was in use. The signals from the temperature sensor and the attenuated outputs from the two Keithley 147's were recorded sequentially at $4 \mathrm{sec}$ intervals with a Leeds and Northrup Speedomax G six-point recorder operating at a chart speed of $5 \mathrm{~cm} / \mathrm{min}$. The sequence was $A, B, C$,

2 V. Rowe, Ph.D. thesis, Michigan State University, 1967 (unpublished)

${ }^{3}$ G. R. Caskey and D. J. Sellmyer, J. Appl. Phys. 40, 1476 (1969).

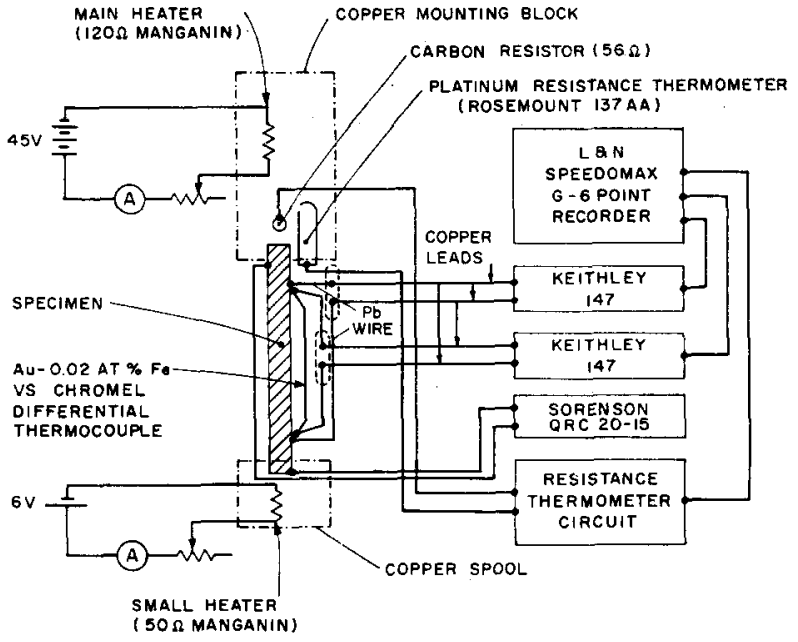

FIG. 1. Schematic circuit diagram for measurement of thermoelectric power and resistivity of rod-shaped specimens.

$B, C, B$, where $A$ is the specimen temperature, $B$ is the voltage of the differential thermocouple, and $C$ is the thermoelectric voltage of the specimen. ${ }^{4}$

Spurious thermal voltages were present in the signals from the specimen and differential thermocouple which varied as the specimen temperature changed but which remained constant once an equilibrium temperature was attained. After the signals reached a steady level, the thermal voltages were suppressed and an arbitrary zero point set with the zero suppression circuits in the Keithley 147's. A temperature gradient of slowly increasing magnitude was then generated by passing current of between 5 to $30 \mathrm{~mA}$ through the small heater on the free end of the specimens. The deviation of the signals as a function of time from the arbitrary points for the specimen and differential thermocouple is shown as recorded in Fig. 2(a).

The thermoelectric power is extracted from the recorded data as follows: A smooth curve is drawn through the points representing the temperature gradient and interpolated to obtain values corresponding in time to the specimen voltage points; a graph of specimen voltage vs the voltage output of the differential thermocouple is made as shown in Fig. 2(b), a straight line is fitted to the data, and the slope determined. The thermoelectric power of the thermocouple consisting of the specimen $(X)$ and lead $(\mathrm{Pb})$ is given by

$S(\mathrm{~Pb} / X)=($ slope $) \cdot \frac{R(X)}{R(\Delta T)} \cdot S(\mathrm{AuFe})=S(\mathrm{~Pb})-S(X)$,

where $S(\mathrm{~Pb} / X)$ is the thermoelectric power of the thermocouple, $R(X)$ the range setting on Keithley 147 for speciment voltage, $R(\Delta T)$ the range setting on Keithley 147

${ }^{4}$ A similar recording technique for thermal conductivity measurements has been described by M. G. Holland and L. G. Rubin, Rev. Sci. Instrum. 33, 923 (1962). 

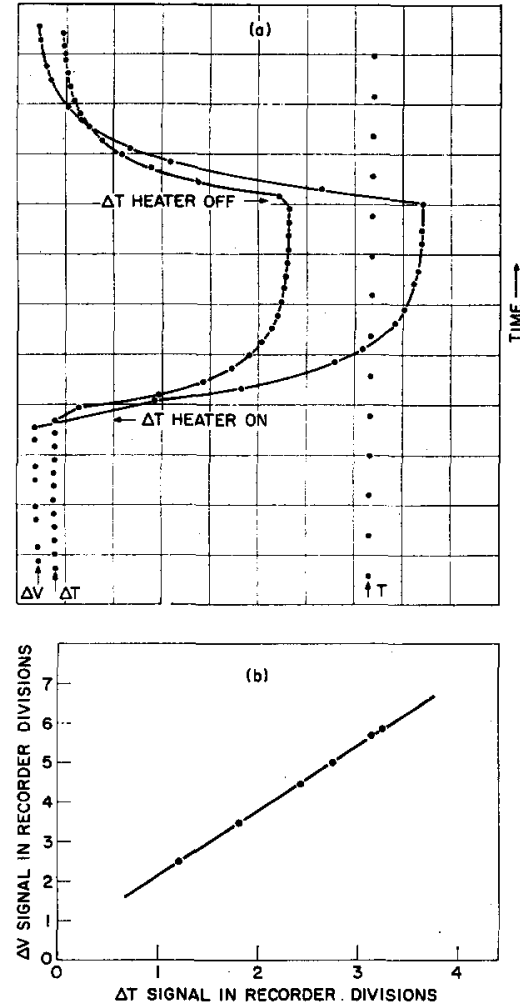

FIG. 2. (a) Example of recorder plot of signals from specimen, differential thermocouple, and platinum or carbon resistance ther mometer. (b) Example of $\Delta V$ vs $\Delta T$ obtained from the raw data in (a).

for differential thermocouple, $S(\mathrm{AuFe})$ the thermoelectric power of the $\mathrm{Au}-\mathrm{Fe} / \mathrm{Chromel} \mathrm{differential} \mathrm{thermocouple,}$ $S(\mathrm{~Pb})$ the thermoelectric power of pure lead, and $S(X)$ the thermoelectric power of specimen. The gold- 0.02 at. $\%$ iron/Chromel thermocouple used for these measurements was calibrated with the conventional integral technique from 4 to $320 \mathrm{~K}$, as shown in Fig. 3 ; it is seen that this combination of materials has a rather high sensitivity over the whole of this temperature region. ${ }^{5}$

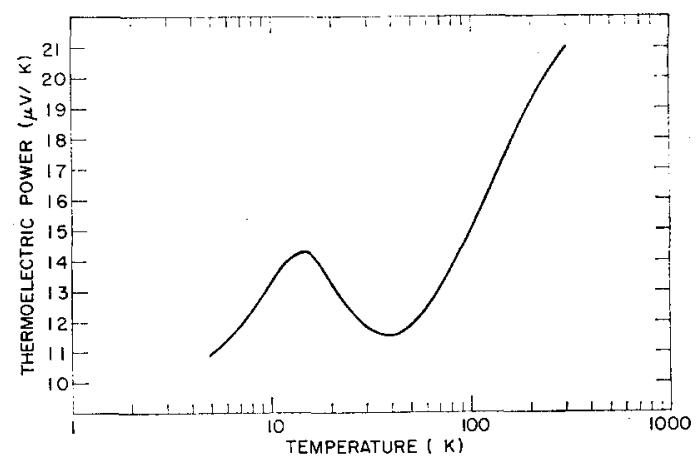

FIg. 3. Thermoelectric power of gold -0.02 at. $\%$ iron/Chromel between 4.2 and $300 \mathrm{~K}$.

${ }^{5}$ For recent research and references on these thermocouples, see R. L. Rosenbaum, Rev. Sci. Instrum. 39, 890 (1968).

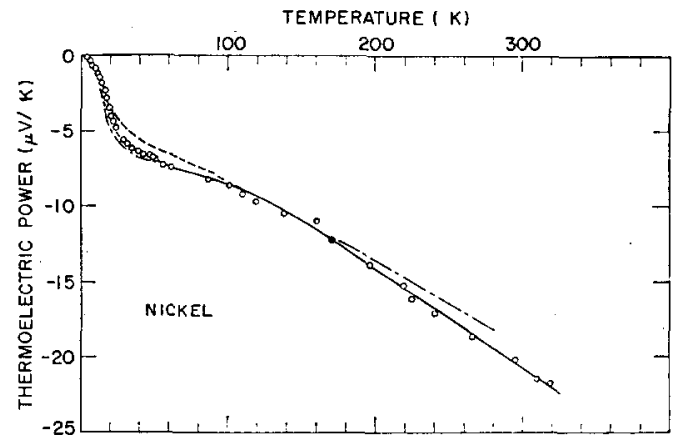

FIg. 4. Thermoelectric power of pure nickel from 4.2 to $300 \mathrm{~K}$. - $\mathrm{O}-\mathrm{p}$ present work, - - - - - Blatt et $\mathrm{al.}$. - - - Grieg and Harrison.

As an example of results obtained with this technique, the measured thermoelectric power of pure -nickel (Johnson, Matthey and Co., Ltd., $99.999 \% \mathrm{Ni}$ rod) is compared with the data of Blatt et al. ${ }^{6}$ and Grieg and Harrison ${ }^{7}$ in Fig. 4. Agreement of all three sets of data is good over the temperature range considered.

Uncertainties in determination of the thermoelectric power are as follows. The estimated error in measurement of the slope used in Eq. (3) is $\pm 2 \%$. This, combined with an uncertainty of $\pm 2 \%$ in the gold-iron/Chromel calibration, gives an uncertainty of about $\pm 4 \%$ for the thermopower of the $\mathrm{Pb} / X$ couple; also, the thermopower of lead is known only to $\pm 1 \%$.

Typically, a total of 50 to 60 measurements of the thermoelectric power was made over the temperature range 4.2 to $300 \mathrm{~K}$ in a period of 8 to $10 \mathrm{~h}$. This time could have been shortened somewhat if an automatic temperature controller had been employed. At the higher temperatures, stabilization of the temperature took as much as 10-15 min.

The main advantage of this system is a significant reduction in the time required to collect the raw data for thermoelectric power measurement. There is a potential saving in cost of liquid helium because of the reduced experimental time. As it now stands there is still a considerable time required to reduce the raw data to a plot of thermoelectric power against temperature. This may be eliminated, if it is desired, by digitizing the analog signals and recording them on paper tape for automatic computer analysis.

${ }^{6}$ F. J. Blatt, D. J. Flood, V. Rowe, P. A. Schroeder, and J. E. Cox, Phys. Rev. Lett. 18, 395 (1967).

'D. Grieg and J. P. Harrison, Phil. Mag. 12, 71 (1965). 